\title{
The Built Environment for Professionalism
}

\author{
Robert L. Phillips, Jr, MD, MSPH
}

The social contract between the public and health professions is fraying, challenged by changes in the organization and financing of health care, and by a collective failure to meet some of the expectations of society. It is timely for family medicine to acknowledge the social contract, to accept responsibility for its the role in renegotiating this contract, and to partner with other practice communities in doing so. Human behavior is strongly directed by our environment and risk aversion rather than rational decision making and it is possible to design our practice environment to "nudge" clinician behaviors purposefully toward professionalism. Current leveraging of professionalism is a path to burnout and the alternative is to create a built environment for good care that also supports professionalism rather than taking advantage of it. There are good examples to draw on, and further experimentation, partnerships, policy, and facilitation of practice redesign are needed to get there. ( $\mathrm{J}$ Am Board Fam Med 2020;33:S57-S61.)

Keywords: Built Environment, Contracts, Delivery of Health Care, Medica Ethics, Primary Health Care, Professionalism

Drs Sylvia and Richard Cruess have long served the profession of medicine in reminding us that the privileges we enjoy as physicians is only half of a contract with society, which requires reciprocity. ${ }^{1}$ In exchange for prestige, respect, trust, autonomy, self regulation, and various rewards, physicians agree to be altruistic, self regulate well, be trustworthy, and address the concerns of society. That social contract is fraying, challenged by changes in the organization and financing of health care, and by a collective failure to meet some of the expectations of society. ${ }^{2}$ The Cruesses also acknowledge that the acculturation of this contract is a feature of a "community of practice," not only in how physicians collectively negotiate and renegotiate the social contract, but in how we train the next generation of physicians. In this response to the Cruesses' valuable discussion, this article describes the need to change the clinical environment to enable and

This article was externally peer reviewed.

Submitted 30 November 2019; revised 18 April 2020; accepted 27 April 2020.

From the Center for Professionalism and Value in Health Care, American Board of Family Medicine Foundation, Washington, DC.

Funding: None.

Disclosures: None.

Corresponding author: Robert L. Phillips, MD, MSPH, Center for Professionalism and Value in Health Care, 1016 NW 16th St, Suite 700, Washington, DC 20036 (E-mail: bphillips@theabfm.org). support the professional behaviors that are critical to healing relationships and shaping the next generation of healers. It offers previously published definitions of a family physician that offer guidance for what good policies could enable and where bad policies are taking us, and it points to policy needs to suppot application of systems engineering and "nudge" principles to enable professional behavior.

Resident physicians steep in that culture and are imprinted by the behaviors they witness around them. ${ }^{3,4}$ Somewhere between didactic education about professionalism and experiences in clinical training, residents become practicing physicians who may or may not exhibit professional behavior. Conflicts between what they are taught about professionalism and what they witness in the clinical setting may even lead to cynicism about professionalism. The Cruesses also acknowledge that the training environment is also a clinical environment that is affected and shaped by changing expectations, particularly value-based payment, quality measurement, accountability expectations, increasing patient autonomy, and loss of value of healing relationships. In light of these external forces, they call for increased intentionality-for family medicine to acknowledge the social contract, to accept responsibility for its the role in renegotiating this contract, and for partnering with other practice communities in doing so too. For training, this means that the 
Figure 1. Family Medicine role definitions. Adapted from Phillips RL Jr, Brundgardt S, Lesko SE, et al. The future role of the family physician in the United States: a rigorous exercise in definition. Ann Fam Med 2014;12:250-5.

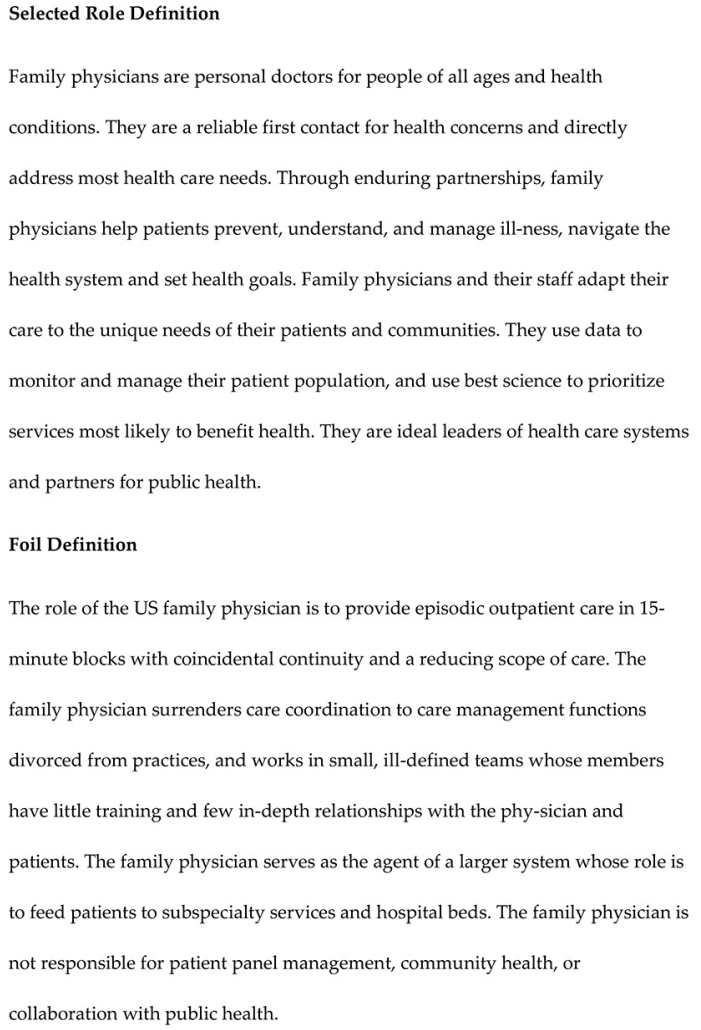

clinical environment should intentionally promote professional behavior.

I appreciate this call for family medicine's responsibility and leadership and contend that intentionality is not enough. As family physicians, we counsel patients every day that intention is not enough, it must be linked to behavior to change outcomes. In recent years, the Nobel Prize has repeatedly gone to psychologists and economists who have discovered that our behaviors are not generally rational. Our decisions are more frequently guided by biases and risk aversion. ${ }^{5}$ However, behavior can be "nudged" in desirable directions without constraining choices by the ways in which options are presented or enabled. ${ }^{6}$ The US and UK governments have been influenced by this new science and created special units to develop policies that use "nudge" principles to guide better outcomes such as increasing organ donor registration. ${ }^{7}$ Another example is school lunch programs that restructure food presentation or ordering and increase student selection of healthier food options. ${ }^{8}$ I have argued that the health system could use similar principles to guide clinician behaviors and support professional intentions-using nudge principles to develop a built environment for health care that makes the right choice the easy choice. ${ }^{9}$ The Institute of Medicine and National Academy of Engineering strictly called for more systems engineering principles, but I believe there is a need to blend system design with behavioral psychology, or "nudge." ally as the application of Bauhaus principle, "form follows function."11 Lesser and colleagues also captured the blending of these sciences, saying, "professional behaviors are profoundly influenced by the organizational and environmental context of contemporary medical practice, and these external forces need to be harnessed to support-not inhibit-professionalism in practice." 12

The 2013 report by the National Academy of Engineering and the Institute of Medicine highlighted that clinicians are currently required to make heroic efforts to do the right thing for patients when clinical design or policies made it difficult to do so. A recent New York Times article made a related accusation that health systems "exploit professionalism."13 That professionalism is what clinicians exhibit despite the system we work in-or that the system counts on our professionalism as a default for system failures-is a recipe for burnout. Being expected to expend personal time, effort, and resources to do the right thing for which current quality measurement and payment offer no rewards, and which clinical design does note enable, can move beyond burnout and into callousness, and can harm patients. ${ }^{14}$

The blend of system engineering and behavioral economics is sorely needed in health care. Clinicians are themselves part of patients' therapy-trust, relationships, appreciation of patients' goals and values, nonjudgemental coaching, and advocacy for them at critical times are important features of healing. When clinicians are burned out or even callous, healing is impaired. When clinicians are guided to and supported in doing the right thing, healing can occur. ${ }^{15}$ I would argue that the built environment for good care is tightly related to that for supporting professionalism. The new and foil definitions of a family physician that were developed to help guide family medicine for America's Health in 2014 are very relevant to this argument (Figure 1). ${ }^{16}$ The foil 
Table 1. Enabling Professionalism via a Built Environment

\begin{tabular}{|c|c|c|}
\hline Enabler & Work To Be Done & Examples \\
\hline Experimentation & $\begin{array}{l}\text { Systems engineering testing } \\
\text { Behavioral economics testing }\end{array}$ & $\begin{array}{l}\text { Sinsky et al, }{ }^{24} \text { Chokshi et al, }{ }^{33} \text { Robertson } \\
\text { et al, }{ }^{34} \text { Volpp et a }{ }^{35}\end{array}$ \\
\hline Implementation partnerships & $\begin{array}{l}\text { Development and implementation of teams and } \\
\text { environments that guide people to best } \\
\text { behaviors and choices }\end{array}$ & Kangovi et al, ${ }^{36}$ Sinsky, ${ }^{27}$ Smith et al ${ }^{17}$ \\
\hline Policy & Clinical and payment policies that enable change & $\begin{array}{l}\text { Sinsky, }{ }^{27} \text { Basu et al, }{ }^{37} \text { Peikes et al, }{ }^{38} \text { Smith } \\
\text { et al, }{ }^{17} \text { Phillips et al, }{ }^{18}\end{array}$ \\
\hline Facilitation & Facilitation that enable change & $\begin{array}{l}\text { Phillips et al, }{ }^{28,39} \text { Cohen et al, }{ }^{40} \text { Kaufman } \\
\text { et al, }{ }^{41} \text { Ono et al, }{ }^{42} \text { Adler et al }{ }^{43}\end{array}$ \\
\hline
\end{tabular}

definition continues to elicit laughs and groans when it is presented because it is such a mirror for what family medicine is becoming. The new definition still holds up for succinctly describing what a family physician might experience if supported differently. The differences in the definitions relate to very different incentives, measures, accountabilities, and relationships. Supporting such a shift cannot be left to intention but requires fundamental changes to financing and clinical design. While these changes require more investment up front, there are good examples that they are eventually cost neutral or associated with significant savings. ${ }^{17-23}$

Coming back to the Cruess's admonitions, facilitating professionalism via a built environment calls for experimentation, partnerships, policy, and implementation (Table 1). Again, the relationship between a built environment for professionalism and one that supports effective primary care is very tight, and while the experimentation, partnership, and advocacy base for the former is just forming, that for the latter is becoming more robust. For example, Bodenheimer and Sinsky reverse engineered discovery of high-functioning and high-joy practices to produce systematic approaches to the redesign of primary care clinics. ${ }^{24-26}$ Their work has likewise led to advocacy for policies supporting clinical redesign. ${ }^{27}$ The Centers for Medicare \& Medicaid Services and Agency for Health care Research and Quality have just completed a national demonstration project and study, respectively, of facilitated practice transformation which are still being evaluated but are likely to produce design and policy options. ${ }^{28}$ Family Medicine for America's Health spawned the Primary Care Innovators Network that produced a series of practical resources around practice and payment to support more effective primary care. ${ }^{29}$ These tools include a payment calculator designed to support the broader necessary functions of robust primary care and population health. This is important because, currently, primary care is $2.12 \%$ of total Medicare spending and $5 \%$ to $7 \%$ of total spending by all payors. ${ }^{30,31}$ The Centers for Medicare \& Medicaid Services recently built on what it has learned from the Comprehensive Primary Care Plus initiative to address this payment disparity in proposing a new payment model for primary care that could enhance payments by $50 \%$ or more. ${ }^{32}$ These are just a few examples offered to illustrate the nonsystematic translation of experimentation into practice and policy to support primary care. For primary care, it would be helpful to intentionally also test and design for enhancing professionalism in addition to performance, but to the extent that these change the built environment for primary care, professionalism may be a residual benefit.

I am most grateful to Drs Sylvia and Richard Cruess for focusing their careers on understanding the social contract for health care and for emphasizing its relevance for the 50th anniversary of the American Board of Family Medicine's founding. Key Aims of the Center for Professionalism \& Value in Health Care are to investigate current understanding and value for the social contract and to promote practice and policy solutions to support professionalism. I believe that the built environment is critical to supporting practical professionalism and that without this intention, professionalism, and patient care will continue to suffer.

To see this article online, please go to: http://jabfm.org/content/ 33/Supplement/S57.full.

\section{References}

1. Cruess SR, Johnston S, Cruess RL. "Profession": a working definition for medical educators. Teach Learn Med 2004;16:74-6. 
2. Wynia M. The short history and tenuous future of medical professionalism: the erosion of medicine's social contract. Perspect Biol Med 2008;51: 565-78.

3. Phillips RL, Jr, Petterson SM, Bazemore AW, Wingrove P, Puffer JC. The Effects of training institution practice costs, quality, and other characteristics on future practice. Ann Fam Med 2017;15:140-8.

4. Cohen JJ. Honoring the "E" in GME. Acad Med 1999;74:108-13.

5. Kahneman D, Tversky A. Prospect theory: an analysis of decision under risk. Econometrica 1979;47:263-91.

6. Thaler R, Sunstein C. Nudge: improving decisions about health, wealth, and happiness. New Haven, CT: Yale University Press; 2008.

7. Whyte KP, Selinger E, Caplan AL, Sadowski J. Nudge, nudge or shove, shove-the right way for nudges to increase the supply of donated cadaver organs. Am J Bioethics 2012;12:32-9.

8. Patel MS, Volpp KG. Nudging students toward healthier food choices-Applying insights from behavioral economics. JAMA Pediatr 2015;169:425-6.

9. Phillips RL, Bazemore AW, Newton WP. Pursuing practical professionalism: form follows function. Ann Fam Med 2019;17:472-5.

10. Kaplan G, Bo-Linn G, Carayon P, et al. Bringing a systems approach to health. Washington, DC: Institute of Medicine and National Academy of Engineering; 2013.

11. Grumbach K. Redesign of the health care delivery system: a Bauhaus "form follows function" approach. JAMA 2009;302:2363-4.

12. Lesser CS, Lucey CR, Egener B, Braddock CH, 3rd, Linas SL, Levinson W. A behavioral and systems view of professionalism. JAMA 2010;304:2732-7.

13. Ofri D. The business of health care depends on exploiting doctors and nurses; one resource seems infinite and free: the professionalism of caregivers. New York Times. June 8, 2019.

14. Panagioti M, Geraghty K, Johnson J, et al. Association between physician burnout and patient safety, professionalism, and patient satisfaction: a systematic review and meta-analysis. JAMA Intern Med 2018;178:1317-31.

15. Rollow $W$, Cucchiara P. Achieving value in primary care: the primary care value model. Ann Fam Med 2016;14:159-65.

16. Phillips RL, Brungardt S, Lesko SE, et al. The future role of the family physician in the United States: a rigorous exercise in definition. Ann Fam Med 2014;12:250-5.

17. Smith PC, Lyon C, English AF, Conry C. Practice transformation under the university of colorado's primary care redesign model. Ann Fam Med 2019;17:S24-S32.
18. Phillips RL, Han M, Petterson SM, Makaroff LA, Liaw WR. Cost, utilization, and quality of care: an evaluation of Illinois' Medicaid primary care case management program. Ann Fam Med 2014;12:408-17.

19. Denham AC, Hay SS, Steiner BD, Newton WP. Academic health centers and community health centers partnering to build a system of care for vulnerable patients: lessons from Carolina Health Net. Acad Med 2013;88:638-43.

20. De Maeseneer JM, De PL, Gosset C, Heyerick J. Provider continuity in family medicine: does it make a difference for total health care costs? Ann Fam Med 2003;1:144-8.

21. Saultz JW, Lochner J. Interpersonal continuity of care and care outcomes: a critical review. Ann Fam Med 2005;3:159-66.

22. Bazemore A, Petterson S, Peterson LE, Bruno R, Chung Y, Phillips RL. Higher primary care physician continuity is associated with lower costs and hospitalizations. Ann Fam Med 2018;16:492-7.

23. Bazemore A, Petterson S, Peterson LE, Phillips RL, Jr. More comprehensive care among family physicians is associated with lower costs and fewer hospitalizations. Ann Fam Med 2015;13:206-13.

24. Sinsky CA, Willard-Grace R, Schutzbank AM, Sinsky TA, Margolius D, Bodenheimer T. In search of joy in practice: a report of 23 high-functioning primary care practices. Ann Fam Med 2013;11:272-8.

25. American Medical Association. AMA launches STEPS Forward to address physician burnout [press release]. 2015. Available from: https:/www.ama-assn.org/ press-center/press-releases/ama-launches-stepsforward-address-physician-burnout.

26. Bodenheimer T, Ghorob A, Willard-Grace R, Grumbach K. The 10 building blocks of highperforming primary care. Ann Fam Med 2014; 12:166-71.

27. Sinsky CA. Designing and regulating wisely: removing barriers to joy in practice. Ann Intern Med 2017;166:677-8.

28. Phillips RL, Cohen DJ, Kaufman A, Dickinson WP, Cykert S. Facilitating practice transformation in frontline health care. Ann Fam Med 2019;17:S2-S5.

29. Primary Care Collaborative. Primary Care Innovators Network Overview. PCC. Available from: https:// www.pcpcc.org/pcin. Published 2019. Accessed November 30, 2019.

30. Reid R, Damberg C, Friedberg MW. Primary care spending in the fee-for-service medicare population. JAMA Intern Med 2019;179:977-80.

31. Jabbarpour Y, Greiner A, Jetty A, et al. Investing in primary care: a state-level analysis: PCPCC annual evidence report. 2019. Available from: https:// www.pcpcc.org/sites/default/files/resources/pcmh_ evidence_report_2019_0.pdf.

32. McConnell KJ. Investing in Primary care anddismantling fee-for-service. Milbank Q 2019;97:636-40. 
33. Chokshi SK, Troxel A, Belli H, et al. User-centered development of a behavioral economics inspired electronic health record clinical decision support module. Stud Health Technol Inform 2019;264:1155-8.

34. Robertson $T$, Darling $M$, Leifer J, Footer $\mathrm{O}$, Gordski D. Behavioral design teams: the next frontier in clinical delivery innovation? Issue Brief (Commonw Fund) 2017;2017:1-16.

35. Patel MS, Volpp KG, Asch DA. Nudge units to improve the delivery of health care. $\mathrm{N}$ Engl J Med 2018;378:214-6.

36. Kangovi S, Mitra N, Norton L, et al. Effect of community health worker support on clinical outcomes of low-income patients across primary care facilities: a randomized clinical trial. JAMA Intern Med 2018;178:1635-43.

37. Basu S, Phillips RS, Song Z, Bitton A, Landon BE. High levels of capitation payments needed to shift primary care toward proactive team and nonvisit care. Health Aff (Project Hope) 2017; 36:1599-605.

38. Peikes D, Dale S, Ghosh A, et al. The comprehensive primary care initiative: effects on spending, quality, patients, and physicians. Health Aff (Project Hope) 2018;37:890-9.

39. Phillips RL, Kaufman A, Mold JW, et al. The Primary Care Extension Program: A Catalyst for Change. Ann Fam Med 2013;11:173-8.

40. Cohen DJ, Balasubramanian BA, Gordon L, et al. A national evaluation of a dissemination and implementation initiative to enhance primary care practice capacity and improve cardiovascular disease care: the ESCALATES study protocol. Implement Sci 2016;11:86.

41. Kaufman A, Powell W, Alfero C, et al. Health extension in New Mexico: an academic health center and the social determinants of disease. Ann Fam Med 2010;8:73-81.

42. Ono SS, Crabtree BF, Hemler JR, et al. Taking innovation to scale in primary care practices: the functions of health care extension. Health Aff (Project Hope) 2018;37:222-30.

43. Adler RN, Ferguson WJ, Antar H, et al. Transformation support provided remotely to a national cohort of optometry practices. Ann Fam Med 2019;17:S33-S39. 